\title{
The Correlation Between Maternal Hemoglobin Concentration and Neonatal Birth Weigth in Kirana Maternal Hospital
}

\author{
Ni Nyoman Yeyen Abriyani, ${ }^{1, *}$ \\ ${ }^{1}$ Faculty of Health Sciences, Universitas Kediri, Kediri, Indonesia \\ 1yeiyen_abriyani@yahoo.com* \\ * corresponding author \\ Submission date: 10 Juli 2018, Receipt date: 10 Oktober 2019, Publication date: 1 Juli 2020
}

\begin{abstract}
World Health Organization (2014) data shows that Maternal Mortality Rate in the world reached 289,000 inhabitants. Indonesian Demographic Health Survey in 2012 mentioned that the maternal mortality rate (MMR) in Indonesia reached 359 / 100,000 live birth. Low hemoglobin levels in pregnant women can cause anemia. It can also increase the frequency of complications in pregnancy and childbirth as well as increase the risk of maternal mortality, the rate of prematurity, low birth weight. This study aims to determine the correlation between hemoglobin levels of pregnant women and birth weight at Kirana Maternal Hospital. This study applied a correlational study using cross sectional design. The data types used This study applied a correlational study using cross sectional design. The data types used secondary data obtained from medical records and maternal health book. The results of the study later in the normality test and analyzed using Pearson test. The results showed that there was no study later in the normality test and analyzed using Pearson test. The results showed that there was no significant correlation between hemoglobin levels of pregnant women and birth weight in Kirana Maternal Hospital in 2016 with 0.00 significance value $<0.05$
\end{abstract}

Keywords: maternal, hemoglobin concentration, birth weight

\section{INTRODUCTION}

Anemia affects 1.62 billion people globally ${ }^{1}$. The prevalence of anemia in developing countries estimated $43 \%$, and about $9 \%$ occurred in developed countries. Anemia is estimated to contribute to more than 115,000 prenatal deaths and 519,000 maternal deaths per year globally ${ }^{2}$, Anemia occurs at all stages of the life cycle but the risk will be higher occurring in pregnancy since it is caused by increasing iron needs, physiological changes during pregnancy and infection ${ }^{3}$. Anemia is a condition in which the number and size of red blood cells or hemoglobin concentration is below the normal limit value (11 g / dl). Consequently, it can interfere the blood's capacity to transport oxygen throughout the body. Anemia in pregnant women is associated with mortality and morbidity of mothers and babies, miscarriage, stillbirth, prematurity and low birth Rate (MMR) in the world at 289,000 inhabitants. $40 \%$ of maternal mortality rate in developing countries are associated with anemia in pregnancy is caused by iron deficiency and acute hemorrhage ${ }^{4}$. Based on the 2012 Indonesian Demographic Health Survey, maternal mortality rate (MMR) in Indonesia reached 359 / 100,000 live birth. In Indonesia, the main cause of maternal mortality rate include bleeding, hypertension 
during pregnancy and infection. Bleeding occupies the highest percentage of maternal mortality in Indonesia (30.1\%). According to the data of Basic Health Survey (2013), it showed that there were $37.1 \%$ of pregnant women suffering from anemia with hemoglobin levels $<11 \mathrm{~g} / \mathrm{dl}$. In 2012, ministry of health created a program in expanding maternal and neonatal survival to reduce maternal and infant mortality focused on the six provinces that had high maternal and infant mortality rates namely North Sumatra, West Java, Central Java, East Java and South Sulawesi ${ }^{5}$.

Hemoglobin ( $\mathrm{hb}$ ) is a component of red blood cells that function to distribute oxygen throughout the body. Iron is a raw material for making red blood cells. Pregnant women with iron deficiency can lead to anemia, because iron cannot bind to hemoglobin in the blood. If hemoglobin rate is low, the body tissue will lack of oxygen. Oxygen is needed to boost the metabolism of pregnant women's body. Pregnant women with high metabolism process has a high metabolic rate that can make the body tissues of the fetus and can also produce energy to pregnant women to remain normal daily activities ${ }^{6}$. Anemia in pregnancy is a condition in women with hemoglobin levels $<11$ $\mathrm{g} / \mathrm{dl}$ in the first and third trimester or the hemoglobin level $<10.5 \mathrm{~g} / \mathrm{dl}$ in the second trimester. Hemoglobin $(\mathrm{Hb})$ greatly affects neonates' birth weight ${ }^{7}$.

Low hemoglobin levels in pregnant women can cause anemia in pregnant women, abortion, a prolonged labor, postpartum hemorrhage, premature birth of under 37 weeks gestational age, low birth weight, and the possibility of born with congenital defects. Anemia also causes low physical ability for the body's cells because it does not get enough oxygen supply. Anemia also increases the frequency of complications in pregnancy and childbirth, the risk of maternal mortality, the rate of prematurity, low birth weight and increased perinatal mortality, as well as postpartum bleeding ${ }^{7}$. A research conducted by Seung, et al (2011) showed that pregnant women who experienced decreasing $\mathrm{Hb}$ levels during late pregnancy were at risk for having a baby with low birth weight. One effort that can be done to improve hemoglobin levels in pregnant women are to give Fe tablets during pregnancy visit, consume meat, eggs, milk, beans, nuts, vegetables such as beets and spinach and regularly consume iron tablet $^{8}$.

Uzma et al (2014) mentioned that pregnant women with anemia who had hemoglobin levels <11 g / dl had higher risk in having low birth weight infant compared with mothers who were not anemic. Based on the description above, the researchers were interested in conducting research with the title of "The Correlation between Hemoglobin Level in Pregnant Women with Newborn's Weight ${ }^{9}$.

\section{RESEARCH METHODS}

This study applied a descriptive correlational study design and analytical study using cross sectional study design. Data used is secondary data were derived from medical records and maternal health books. Kirana Maternal Hospital. The population in this study were all women giving birth in Kirana Maternal Hospital. The samples were done in nonprobability sampling with purposive sampling technique which consists of inclusion and exclusion criteria. The independent variables was hemoglobin levels of pregnant women. The dependent variable was the weight of the newborn. Data analysis applied data normality test. Test of data normality used the Shapiro-Wilk test. When the results showed the distribution of normal data, the Pearson test was used to measure the strength and the linear relationship of two variables. 


\section{RESULTS AND DISCUSSION}

Univariate analysis

Table 1. The frequency distribution of respondent's characteristics on the correlation between hemoglobin levels of pregnant women and the weight of newborn babies in Kirana Maternal Hospital,

\begin{tabular}{lcc}
\multicolumn{1}{c}{ Characteristics } & 2016 & \% \\
\hline Mother's age & F & \\
20-25 years & 20 & 66.7 \\
$26-31$ years & 8 & 26.7 \\
$>32$ years & 2 & 6.7 \\
& $\mathbf{3 0}$ & $\mathbf{1 0 0}$ \\
\hline Hemoglobin levels & & \\
$<11 \mathrm{~g} / \mathrm{dl}$ & 14 & 46.7 \\
$>11 \mathrm{~g} / \mathrm{dl}$ & 16 & 53.3 \\
& $\mathbf{3 0}$ & 100 \\
\hline Weight of newborns & & \\
$<2,500 \mathrm{~g}$ & $\mathbf{1 1}$ & 36.7 \\
$>2,500 \mathrm{~g}$ & $\mathbf{1 9}$ & 63.3 \\
& $\mathbf{3 0}$ & 100 \\
\hline
\end{tabular}

Based on Table 1, it was found that of the 30 mothers who were respondents mostly in the age group of $20-25$ years of the $20(66.7 \%)$ mothers. Based on the characteristics of the maternal hemoglobin levels, the majority of respondents have a hemoglobin level $>$ $11 \mathrm{~g} / \mathrm{dl}$ as many as 16 respondents (53.3\%) and weight of newborns $>2,500 \mathrm{~g}$ were 19 infants $(63.3 \%)$.

Bivariate Analysis

Table 2. Results of normality test on the correlation between hemoglobin levels in pregnant women and newborn weight in Kirana Maternal Hospital in 2016.

\begin{tabular}{|c|c|c|c|}
\hline Data & $\begin{array}{ll}\text { g } & \text { Si } \\
\end{array}$ & $\mathbf{A}$ & Information \\
\hline Hemoglobin level and weight newborns & 0.464 & 0.05 & normal \\
\hline
\end{tabular}

Based on Table 2, it appears that significant value to Shapiro-Wilk test hemoglobin levels of pregnant women and newborn weight was $>0.05$. This shows that the sample obtained normal distribution in the hemoglobin level and body weight newborns.

Table 3. Pearson test hemoglobin levels and weight newborns

\begin{tabular}{lcccc}
\hline & & Pearson correlation & Sig.(2-tailed) & N \\
\hline $\begin{array}{l}\text { Hemoglobin levels of } \\
\text { women and newborn weight }\end{array}$ & 0.813 & 0 & 30 \\
\hline
\end{tabular}


Based on the significant value, if the significance value $>0.05$, there was no correlation or relationship and vice versa if the significance value $<0.05$, and it showed that there was a relationship between hemoglobin levels of pregnant women and newborn weight with 0.00 probability value $<0.05$, meaning that there was a relationship. The hemoglobin levels of pregnant women and newborn weight gained 0.00 probability value $<0.05$ meaning that there was a significant correlation between hemoglobin of pregnant women with birth weight.

\section{The Correlation between Hemoglobin Levels of Pregnant Women and Birth Weight}

Among 30 newborns in Kirana Maternal Hospital in Sidoarjo, there were 11 babies with low birth weight of $<2500 \mathrm{~g}$. Those low birth weight babies were born from pregnant women with hemoglobin $<11 \mathrm{~g} / \mathrm{dl}$. Low hemoglobin in pregnant women caused the patients not able to disburse oxygen, nutrients to the fetus so that the growth and development of the fetus will be blocked. Pregnant women who had a low hemoglobin level had a great chance to give birth to babies with the weight below the normal, because oxygen and nutrients from the mother to the fetus was not carried by the blood of the mother well. If the mother had hb lower than the normal level, it interfered with the function of the placenta to the fetus. Low levels of hb in pregnant women triggered to cause lower oxygen and nutrients distribution that the fetal needed to grow and thrive thus it affected the birth weight. Akhter (2010) explained that anemia during pregnancy significantly harms the newborn including birth weight, Apgar score, and birth asphyxia ${ }^{10}$.

In this study, there was a significant correlation between hemoglobin levels of pregnant women and birth weight of the 30 pregnant women in Kirana Maternal Hospital. There were 16 pregnant women with high levels of normal hb i.e. $>11 \mathrm{~g} / \mathrm{dl}$. There were 19 babies with a normal birth weight i.e. $>2,500 \mathrm{~g}$. In addition, 14 pregnant women with below normal hemoglobin level had 11 infants with abnormal birth weight of $<2500 \mathrm{~g}$. Among 30 respondents pregnant women in Kirana Maternal Hospital, there were 14 respondents with abnormal hb rate of less than $11 \mathrm{~g} / \mathrm{dl}$. This results were in accordance with Nadia (2010) stating that there was a significant association between anemia and newborns birth weight ${ }^{11}$. During pregnant period, the amount of blood volume that is used for the needs of the mother and fetus reduces at the beginning of the third trimester of pregnancy to the end. There is low blood pressure due to the increase in the volume of blood plasma; the addition of body fluids (plasma volume) is not comparable with the addition of the red blood cell mass, resulting in decreased hemoglobin levels. A decrease in hemoglobin levels in pregnant women due to expansion of plasma volume is greater than the increase in the volume of red blood cells and hemoglobin ${ }^{12}$.

The low hemoglobin level in pregnant women affects fetal growth and development. Pregnant women are recommended for getting pregnancy check-up for at least 4 times, especially blood checks on HB levels in TM I and TM III because of a blood-thinning effects. This is in accordance with Seung (2011) mentioning that changing in hemoglobin levels from pregnancy to the end of pregnancy was significantly correlated with a decrease in plasma volume and plasma volume expansion during pregnancy reported to increase the risk of birth weight rendah8. This occurs in the first TM and TM III, while hemoglobin decreased plasma expansion to continue increasing. Body undergoes significant changes during pregnancy. The amount of blood 
in the body increases, thus it requires an increase in the supply of iron and vitamin needs to make hemoglobin. When pregnant, the body makes more blood to share with her baby. According to Macedo (2010), the importance of routine iron supplementation during pregnancy keeps pregnancy complications and maintain iron levels in the blood 12

\section{CONCLUSION}

Prenatal care in the first trimester to the third trimester is crucial in monitoring the health of the mother and the fetus as well as the early detection of pregnancy complications to get proper treatment, to give examination performed on the first trimester to the third trimester, to determine $\mathrm{Hb}$, to monitor the health of mothers and to support fetal growth and development. Consumption of the nutritious food has to meet the needs of the mother and fetus so that the fetus can grow and develop properly, so the baby is born with a normal weight.

\section{REFERENCES}

Balarajan Y, Ramakrishnan sv: anemia in low-income and income and middle income coutries. Lancet, 2013.

Mbule MA, Byaruhanga YB, Kabahenda M, Lubowa A: determinants of anemia among pregnant woment in rural uganda. Remote rural health.2013

Mclean E, Cogswell M, Egli I, Wojdyla D, de Benoist B: World wide prevalence of anemia, WHO Vitamin and mineral nutrition information system, 1993-2005. Public health Nutr 2009

Ministry of Health of the Republic of IndonesiaHealth .2014.Profil Indonesia.Jakarta

MOH RI.2008.Health Development Plan Towards Healthy Indonesia 2010, Jakarta

WHO. Maternal Mortality: World Health Organization; 2014 